\title{
Peritoneal dialysis and infants: further insights into a complicated relationship
}

\author{
Enrico Vidal ${ }^{1}$
}

Received: 22 November 2017 / Revised: 24 November 2017 / Accepted: 24 November 2017 / Published online: 7 December 2017

(C) IPNA 2017

\begin{abstract}
Peritoneal dialysis (PD) in infants represents one of the greatest challenges for pediatric nephrologists. Over recent years, positive outcome data described by several multicenter experiences and registry studies have increased the amount of information available to help determine whether to initiate a dialysis program in this high-risk patient population. There is no doubt that the rigorous implementation of strategies aimed at preventing infectious complications may have contributed to reducing the morbidity rate of these patients. However, the complex nature of infants with end-stage renal disease and the presence of multiple comorbidities still represent hallmarks that significantly impact on outcome. Although the rigorous application of improved scientific techniques can still contribute to enhancing PD results in infants, we have to acknowledge that the severity of illness in infants, especially at dialysis initiation, represents an undeniable and nonmodifiable factor.
\end{abstract}

Keywords Peritoneal dialysis $\cdot$ Infants $\cdot$ Peritonitis $\cdot$ Hospitalization $\cdot$ Quality improvement

\section{Introduction}

An increasing number of publications in recent years have reported satisfactory outcomes with respect to morbidity, mortality, growth, and development in newborns and infants undergoing maintenance peritoneal dialysis (PD) [1-5]. A very young age at dialysis initiation still has a negative prognostic value, but this alone cannot remain a contraindication to any form of renal replacement therapy (RRT). As a consequence, an increasing number of infants are successfully treated with PD, and the question has shifted from whether or not to start dialysis to how to improve dialysis management in these fragile patients.

According to the most recent European Registry for Paediatric Nephrology/European Renal Association-European Dialysis and Transplant Association (ESPN/ERA-EDTA) Registry Annual Report, in 2015, the number of children with end stage renal disease (ESRD) in whom hemodialysis (HD) $(41.6 \%)$ and PD (39.5\%) was initiated was similar [6].

Enrico Vidal

enrico.vidal@inwind.it

1 Pediatric Nephrology, Dialysis and Transplantation Unit, Department of Woman's and Child's Health, University Hospital of Padua, Via Giustiniani 3, 35128 Padua, Italy
However, in small children, PD still represents the dialysis modality of choice [4]. Several studies indicate young age as a risk factor for infectious complications in children on dialysis. The most common complication associated with PD continues to be peritonitis, which is also the most frequent cause for hospitalization in children receiving PD [7, 8]. On the basis of previous studies describing infant dialysis, cohort-specific peritonitis incidence ranges from 0.58 to 1.7 episodes per patient-year [1-3]. In the last annual report of the North American Pediatric Renal Trials and Collaborative studies (NAPRTCS), which includes data collected over a 20-year period, 4248 episodes of peritonitis in 6658 patient-years of follow-up were reported, yielding an annualized rate of 0.64 , or one episode every 18.8 months [9]. The annualized rate decreases with patient age, with the youngest $(<1$ year) having an annualized rate of 0.79 and those older than 12 years 0.57 . Occurrence of peritonitis is associated with high mortality and can also impact on the structure and function of the peritoneal membrane, thus reducing long-term availability of effective dialysis $[7,8]$. Several risk factors can influence the incidence of peritonitis in children, and understanding them is important to optimize prevention and patient outcome. Quality of care received by children on dialysis is essential to minimize long-term complications, and this concept is especially true in infants, who will have a lifetime of RRT ahead of them. 


\section{What we know}

Evidence derived from several registry-based studies has identified factors potentially associated with peritonitis in children on PD. Recognized risk factors are touch contamination, exit site/tunnel infection [10], catheter leakage, oligoanuria [2, 11], and presence of nasogastric tube/gastrostomy [3, 12]. Surgical expertise and antibiotic prophylaxis are keys to minimizing the risks associated with early-onset peritonitis after PD catheter insertion [13]. The risk for developing peritonitis associated with these factors is emphasized during infancy. The catheter design associated with a lower risk of infection in children appears to be the double-cuffed swan-neck catheter with its inherent downward-directed exit site [13]. However, infants with limited abdominal wall, particularly if hypoproteinemic, are at risk of distal cuff extrusion [14], with a subsequent higher risk of leakage, exit site infection, and eventually peritonitis. This risk can be reduced by delaying dialysis onset to 2-3 weeks after implantation and by monitoring intraperitoneal pressure $[15,16]$. Concerns also exist that a downward exit site may be a risk factor for infections in small children using diapers. The proximity of the catheter exit site to the diaper region or to gastrostomy/vesicostomy/ nephrostomy sites has been associated with higher incidence of Gram-negative peritonitis (diaper peritonitis) compared with older children [17]. In some centers, this issue has been successfully addressed by placing the exit site outside the diaper area, in the presternal area [18].

Nutritional management is an essential part of the care of small children receiving dialysis, and tube feeding of infants on PD is mandatory to achieve their growth potential [19]. However, the use of gastrostomy tube/button impacts on the risk for peritonitis. Ledermann et al. reported that the incidence of peritonitis in their gastrostomy-fed infants was twice as great when tube insertion was conducted after, compared with before, dialysis initiation [12]. When supplemental tube feeding is considered likely, prior or concurrent placement of a gastrostomy at the time of PD catheter placement, with appropriate antibiotic and antifungal prophylaxis, decreases the risk of bacterial or fungal infections that can occur soon after PD catheter placement [13]. Percutaneous placement of a gastrostomy tube while on PD should not be performed due to the high risk of infections and mechanical failure [20].

Infants on chronic PD with oliguria frequently have hypoproteinemia and hypogammaglobulinemia as a result of malnutrition and peritoneal protein losses [2]. The presence of hypogammaglobulinemia is commonly complicated by the development of recurrent infections and, specifically, might be a risk factor for the development of bacterial peritonitis in patients receiving PD. There is no evidence for routine IV administration of prophylactic immunoglobulins in all infants [21], but replacement therapy should be considered if very low immunoglobulin levels are found [22, 23].
Hospitalization rates for infants on PD are higher than those for older children [2]. In a NAPRTCS analysis, Carey et al. demonstrated that $\sim 75 \%$ of children $<2$ years required hospitalization while on maintenance dialysis [24]. The last Annual Report of the United States Renal Data System (USRDS) clearly demonstrated an increase in all-cause hospitalization rates of children with ESRD from 2003 to 2007 to 2008-2012 [25]. During the more recent time frame, the rates of 1-year hospitalization were highest in PD patients (2189 admissions per 1000 patient-years) and in the youngest segment of children with ESRD ( $0-4$ years, 3253 admissions per 1000 patient-years). Infection was the leading cause for hospitalization: in children $0-4$ years of age, the overall rate of hospitalization for infection was 1239 admissions per 1000 patient years during 2008-2012, which is $3.3 \%$ higher than during 2003-2007. A recent paper on ESPN/ERAEDTA data showed a gradual decrease over 30 years of follow-up in infection-related hospitalizations in children on PD, except for peritonitis [26]. The greater likelihood of longer hospitalization and the increased risk of complications potentially resulting in additional surgical procedures are factors that significantly impact the biological and economic cost of dialysis for infants. It follows that efforts should be directed to implement all strategies aimed at preventing and reducing peritonitis in infant $\mathrm{PD}$, including using improved scientific models.

\section{A new character: SCOPE collaborative}

The concept of improvement science recently emerged and provides a framework for research focused on healthcare improvement. The overriding goal of improvement science is to ensure that quality-improvement efforts are based both on evidence and best-practice recommendations [27]. Improvement science methods have been used to reduce a variety of healthcare-associated infections in children. A program aimed at preventing peritonitis in children on PD should, therefore, focus on "drivers" known to be associated with PD infections, such as catheter insertion practices, pre- and postoperative care, exit-site management, recognition and treatment of touch contamination, exit-site and tunnel infection, education of dialysis staff, and patient and family engagement strategies [28]. The Children's Hospital Association's Standardizing Care to Improve Outcomes in Pediatric ESRD (SCOPE) Collaborative is a quality-improvement project aimed at reducing PD-associated infections in children on chronic PD, addressing, in a systematic fashion, most of the aforementioned drivers [29]. The objectives of this qualitytransformation effort were to evaluate whether providing compliance with a series of care practice bundles (encompassing PD catheter insertion, patient and caregiver training, and follow-up care) was associated with lower risk for peritonitis 
among pediatric patients on PD. In the first 3 years of the SCOPE Collaborative (1 October 2011 to 30 September 2014), 734 children with a median age of 9 years were enrolled; children $<2$ years represented $32.4 \%$ of the cohort [30]. About one third of patients enrolled $(n=245)$ developed at least one episode of peritonitis, resulting in an annualized peritonitis rate of 0.46 infections per patient-year. Providing compliance with the "training" bundles did not significantly differ between children with and without peritonitis. In contrast, compliance with the follow-up bundle, including reviewing key aspects of hand washing, exit-site care, and aseptic connection technique, resulted in a significantly lower risk of peritonitis. Overall, implementation of three standardized PD catheter-care bundles reduced the monthly annualized peritonitis rate from 0.63 pre-SCOPE Collaborative to 0.42 at 3 years postlaunch [31]. In univariate analysis, the peritonitis group had a significantly higher proportion of patients with gastrostomy tube, incontinence (e.g., in diapers), and report of touch contamination in the month before infection or at last follow-up compared with the group without peritonitis [30]. Comparison of PD catheter characteristics revealed that the peritonitis group had significantly more catheters with upward (rather than downward or lateral) orientation at the exit-site and use of a plastic rather than titanium adapter at the distal end of the catheter [30]. Since its launch, it is estimated that the SCOPE Collaborative has prevented nearly 400 episodes of peritonitis, avoided 240 hospitalizations, and saved more than US\$7 million in healthcare costs [32]. Moreover, the study confirmed that there is still the need and space to intervene against modifiable factors to reduce the burden of peritonitis in PD patients.

\section{SCOPE collaborative and infants}

In this issue of Pediatric Nephrology, using data from the SCOPE Collaborative, Zaritsky et al. examine the epidemiology of peritonitis in 156 infants who had a PD catheter placed in the first year of life [33]. Patients were enrolled at the time of catheter placement, even if chronic care had not been established as an outpatient. This means that the study also included patients who started chronic PD as an inpatient and remained hospitalized. Therefore, these data integrate information obtained from home-based registries and provide a more complete overview about epidemiology and risk factors for peritonitis and the outcome of infants on PD.

The study has three major findings that corroborate or provide new evidence as regards peritonitis in infants on PD. First, data from the SCOPE Collaborative confirm that the annualized peritonitis rates are very high in infants undergoing PD catheter insertion in their first year of life. Specifically, 65 of 156 infants (42\%) had at least one episode of bacterial peritonitis within 1 year, resulting in an overall annualized rate of 0.76 episodes per patient-year. An extremely high incidence of peritonitis was observed early, during the initial hospital stay after PD catheter placement (1.73 episodes per patient-year).

Second, this uneven distribution of peritonitis rates among the same cohort of patients highlights that qualitatively and quantitatively different risk factors are associated with peritonitis in infants started (inpatients) or maintained (outpatients) on PD. Diagnosis of polycystic kidney disease - namely, autosomal recessive polycystic disease (ARPKD), history of pulmonary hypoplasia, the use of a curled PD catheter or plastic adaptor, nephrectomy prior to or concurrent with $\mathrm{PD}$ catheter insertion, and gastrostomy tube insertion after catheter placement - were significantly more common in patients who experienced peritonitis compared to those who did not. Infants with an episode of peritonitis during their initial hospitalization were younger and more likely to have a diagnosis of ARPKD and a history of pulmonary hypoplasia than those who developed peritonitis as outpatients. Moreover, most inhospital cases of peritonitis were associated with the need for nephrectomy. The relative lower incidence of outpatient peritonitis may reflect an exposure to fewer or less-severe risk factors in nonhospitalized infants but may also be due to the type of care patients received by staff and parents trained according to the SCOPE bundles. All variables that gave significant results in univariate analysis were then included in a multivariable logistic regression model. Because of multicollinearity, the only factors independently associated with increased risk of peritonitis in the whole cohort were nephrectomy and gastrostomy tube insertion after PD catheter placement. The last is the only true identified modifiable factor, while nephrectomy is perhaps a surrogate for the diagnosis of ARPKD, a condition associated with severe comorbidities, a higher risk of infection, and increased mortality rates. Unilateral or bilateral nephrectomy often represents an inevitable therapeutic approach to ameliorate respiratory impairment, nutritional management, and facilitate PD initiation.

Third, this study confirms that peritonitis is associated with increased morbidity. It also provides benchmarks for hospitalization in infants starting on PD to compare with other pediatric centers and with ourselves in the future. Infants have a long duration of hospitalization after PD initiation, ranging from a minimum of 60 days to a maximum of 154 days for patients who require nephrectomy, G-tube insertion after PD catheter placement, and with in-hospital peritonitis.

The study of Zaritsky et al. [33] provides new evidence on risk factors associated with the development of peritonitis in infants, especially as regards patients during their initial hospitalization and after PD catheter placement. However, because it was not included within the SCOPE Collaborative primary aims, the authors did not analyze risk for and incidence of other conditions, such as catheter-related (mechanical) or clinical complications. 


\section{Conclusions}

Dialysis-access-associated infections, specifically peritonitis, are leading causes of hospitalization and death among infants receiving PD. The use of clinical practice improvement methods helps prevent infection and, when they occur, initiation of prompt and appropriate treatment, and thus should be included in pediatric PD programs. Infants who develop peritonitis early after PD implantation and while hospitalized have different clinical characteristics than those who only develop peritonitis as an outpatient. Inpatient peritonitis is more frequently associated with nonmodifiable risk factors, including diagnosis of ARPKD, comorbidities, and the need for nephrectomy.

\section{Compliance with ethical standards}

Conflict of interest The author declares he has no conflict of interest.

\section{References}

1. Laakkonen H, Hölttä T, Lönnqvist T, Holmberg C, Rönnholm K (2008) Peritoneal dialysis in children under two years of age. Nephrol Dial Transplant 23:1747-1753

2. Vidal E, Edefonti A, Murer L, Gianoglio B, Maringhini S, Pecoraro C, Sorino P, Leozappa G, Lavoratti G, Ratsch IM, Chimenz R, Verrina E, Italian Registry of Paediatric Chronic Dialysis (2012) Peritoneal dialysis in infants: the experience of the Italian registry of Paediatric chronic dialysis. Nephrol Dial Transplant 27:388-395

3. Hijazi R, Abitbol CL, Chandar J, Seeherunvong W, Freundlich M, Zilleruelo G (2009) Twenty-five years of infant dialysis: a single center experience. J Pediatr 155:111-117

4. Carey WA, Martz KL, Warady BA (2015) Outcome of patients initiating chronic peritoneal dialysis during the first year of life. Pediatrics 136:e615-e622

5. Vidal E, van Stralen KJ, Chesnaye NC, Bonthuis M, Holmberg C, Zurowska A, Trivelli A, Da Silva JEE, Herthelius M, Adams B, Bjerre A, Jankauskiene A, Miteva P, Emirova K, Bayazit AK, Mache CJ, Sánchez-Moreno A, Harambat J, Groothoff JW, Jager KJ, Schaefer F, Verrina E, ESPN/ERA-EDTA Registry (2017) Infants requiring maintenance dialysis: outcomes of hemodialysis and peritoneal dialysis. Am J Kidney Dis 69:617-625

6. ESPN/ERA-EDTA Registry annual report 2015. Department of Medical Informatics, Academic Medical Center, Amsterdam, the Netherlands. Available at: https://www.espn-reg.org/files/AR_ 2015.pdf

7. Chadha V, Schaefer FS, Warady BA (2010) Dialysis-associated peritonitis in children. Pediatr Nephrol 25:425-440

8. Bakkaloğlu SA, Kandur Y, Serdaroğlu E, Noyan A, Bayazıt AK, Sever L, Özlü SG, Özçelik G, Dursun İ, Alparslan C (2017) Effect of the timing of dialysis initiation on left ventricular hypertrophy and inflammation in pediatric patients. Pediatr Nephrol 32:15951602

9. North American Pediatric Renal Trials and Collaborative Studies (NAPRTCS). 2014 Annual Dialysis Report. Available at: https:// web.emmes.com/study/ped/annlrept/annualrept2014.pdf

10. Furth SL, Donaldson LA, Sullivan EK, Watkins SL, North American Pediatric Renal Transplant Cooperative Study (2000) Peritoneal dialysis catheter infections and peritonitis in children: a report of the north American pediatric renal transplant cooperative study. Pediatr Nephrol 15:179-182

11. Boehm M, Vécsei A, Aufricht C, Mueller T, Csaicsich D, Arbeiter $\mathrm{K}$ (2005) Risk factors for peritonitis in pediatric peritoneal dialysis: a single-center study. Pediatr Nephrol 20:1478-1483

12. Ledermann SE, Spitz L, Moloney J, Rees L, Trompeter RS (2002) Gastrostomy feeding in infants and children on peritoneal dialysis. Pediatr Nephrol 17:246-250

13. Warady BA, Bakkaloglu S, Newland J, Cantwell M, Verrina E, Neu A, Chadha V, Yap HK, Schaefer F (2012) Consensus guidelines for the prevention and treatment of catheter-related infections and peritonitis in pediatric patients receiving peritoneal dialysis: 2012 update. Perit Dial Int 32(Suppl 2):S32-S86

14. Rinaldi S, Sera F, Verrina E, Edefonti A, Perfumo F, Sorino P, Zacchello G, Andreetta B, Ardissino G, Bassi S, Capasso G, Caringella DA, Gianoglio B, Gusmano R, Rizzoni G (1998) The Italian registry of pediatric chronic peritoneal dialysis: a ten-year experience with chronic peritoneal dialysis catheters. Perit Dial Int 18:71-74

15. Patel UD, Mottes TA, Flynn JT (2001) Delayed compared with immediate use of peritoneal catheter in pediatric peritoneal dialysis. Adv Perit Dial 17:253-259

16. Aranda RA, Romão Júnior JE, Kakehashi E, Domingos W, Sabbaga E, Marcondes M, Abensur H (2000) Intraperitoneal pressure and hernias in children on peritoneal dialysis. Pediatr Nephrol $14: 22-24$

17. Warady BA, Feneberg R, Verrina E, Flynn JT, Müller-Wiefel DE, Besbas N, Zurowska A, Aksu N, Fischbach M, Sojo E, Donmez O, Sever L, Sirin A, Alexander SR, Schaefer F, IPPR (2007) Peritonitis in children who receive long-term peritoneal dialysis: a prospective evaluation of therapeutic guidelines. J Am Soc Nephrol 18:21722179

18. Rönnholm KA, Holmberg C (2006) Peritoneal dialysis in infants. Pediatr Nephrol 21:751-756

19. Rees L (2007) Long-term peritoneal dialysis in infants. Perit Dial Int 27:S180-S184

20. von Schnakenburg C, Feneberg R, Plank C, Zimmering M, Arbeiter K, Bald M, Fehrenbach H, Griebel M, Licht C, Konrad M, Timmermann K, Kemper MJ (2006) Percutaneous endoscopic gastrostomy in children on peritoneal dialysis. Perit Dial Int 26: 69-77

21. Lalan S, Dai H, Warady BA (2017) Hypogammaglobulinemia in infants receiving chronic peritoneal dialysis. Pediatr Nephrol 32: 503-509

22. Neu AM, Warady BA, Lederman HM, Furth SL, Fivush BA (1998) Hypogammaglobulinemia in infants and young children maintained on peritoneal dialysis. Pediatric dialysis study consortium. Perit Dial Int 18:440-443

23. Zurowska AM, Fischbach M, Watson AR, Edefonti A, Stefanidis CJ, European Paediatric Dialysis Working Group (2013) Clinical practice recommendations for the care of infants with stage 5 chronic kidney disease (CKD5). Pediatr Nephrol 28:1739-1748

24. Carey WA, Talley LI, Sehring SA, Jaskula JM, Mathias RS (2007) Outcomes of dialysis initiated during the neonatal period for treatment of end-stage renal disease: a north American pediatric renal trials and collaborative studies special analysis. Pediatrics 119: e468-e473

25. United States Renal Data System (USRDS) annual data report. Volume 2: ESRD in the United States. National Institutes of Health, National Institute of Diabetes and Digestive and Kidney Diseases, Bethesda

26. Lofaro D, Vogelzang JL, van Stralen KJ, Jager KJ, Groothoff JW (2016) Infection-related hospitalizations over 30 years of follow-up in patients starting renal replacement therapy at pediatric age. Pediatr Nephrol 31:315-323 
27. Shojania KG, Grimshaw JM (2005) Evidence-based quality improvement: the state of the science. Health Aff (Millwood) 24: $138-150$

28. Redpath Mahon A, Neu AM (2017) A contemporary approach to the prevention of peritoneal dialysis-related peritonitis in children: the role of improvement science. Pediatr Nephrol 32:1331-1341

29. Neu AM, Miller MR, Stuart J, Lawlor J, Richardson T, Martz K, Rosenberg C, Newland J, McAfee N, Begin B, Warady BA, Collaborative Participants SCOPE (2014) Design of the standardizing care to improve outcomes in pediatric end stage renal disease collaborative. Pediatr Nephrol 29:1477-1484

30. Sethna CB, Bryant K, Munshi R, Warady BA, Richardson T, Lawlor J, Newland JG, Neu A, SCOPE Investigators (2016) Risk factors for and outcomes of catheter-associated peritonitis in children: the SCOPE collaborative. Clin J Am Soc Nephrol 11:15901596
31. Neu AM, Richardson T, Lawlor J, Stuart J, Newland J, McAfee N, Warady BA, SCOPE Collaborative Participants (2016) Implementation of standardized follow-up care significantly reduces peritonitis in children on chronic peritoneal dialysis. Kidney Int 89:1346-1354

32. Children's Hospital Association. Standardizing Care to Improve Outcomes in Pediatric ESRD Collaborative. Children's Hospital Association. Available at: www.childrenshospitals.org/Programsand-Services/Quality-Improvement-and-Measurement/ Collaboratives/SCOPE. Accessed 16 Nov 2017

33. Zaritsky JJ, Hanevold C, Quigley R, Richardson T, Wong C, Ehrlich J, Lawlor J, Rodean J, Neu A, Warady BA, SCOPE Investigators (2017) Epidemiology of peritonitis following maintenance peritoneal dialysis catheter placement during infancy: a report of the SCOPE collaborative. Pediatr Nephrol. https://doi.org/ 10.1007/s00467-017-3839-5 